\title{
Numerical simulation of the natural, forced and mixed convection in a tunnel with a flat track of sinusoidal shape and a roof opening
}

\author{
Oumar Drame ${ }^{1, *}$, Cheikh Mbow ${ }^{1}$, Florin Bode ${ }^{2}$, Samba Dia $^{1}$, and Omar Ngor Thiam ${ }^{1}$ \\ ${ }^{1}$ Cheikh Anta Diop University of Dakar, Faculty of Science and Technology Department of Physics; fluid mechanics laboratory and \\ applications BP 5005 Dakar-Fann \\ ${ }^{2}$ Technical University of Cluj-Napoca, Dept. of Mechanical Engineering, Bd. Muncii 103-105, 400641, Cluj-Napoca, Romani
}

\begin{abstract}
In this work, we studied the mixed convection of the airflow in a tunnel open at both ends. The tunnel has a sinusoidal trace and the horizontal ceiling is provided with an opening in the center. The tunnel floor is uniformly heated. Although of interest for many industrial applications, the configuration of this study has been studied very little from an academic point of view. Coupled equations of Naiver-Stokes and energy are solved numerically by the finite volume method with the Boussinesq hypothesis. We analyzed the effect of the parameters that characterize heat transfer, and the flow structure. Several situations have been considered by varying the Richardson number $(1.3610-3 \leq \mathrm{Ri} \leq 2.17 .104)$ for a Prandtl number $\operatorname{Pr}=0.71$.
\end{abstract}

\section{Nomenclature}

\begin{tabular}{|c|c|}
\hline$a$ & amplitude of the sinusoidal part (m) \\
\hline$g_{p}$ & gravitational acceleration $\left(\mathrm{ms}^{-2}\right)$ \\
\hline$h$ & $\begin{array}{l}\text { height between the ceiling and the bottom of } \\
\text { the sinusoid }(\mathrm{m})\end{array}$ \\
\hline$h_{e}$ & entrance height of the tunnel $(\mathrm{m})$ \\
\hline$h_{c}$ & convective coefficient $\left(\mathrm{w} \cdot \mathrm{m}^{-2} \cdot \mathrm{k}^{1}\right)$ \\
\hline$L$ & total length of the tunnel (m) \\
\hline$D_{h}$ & hydraulic diameter (m) \\
\hline$l$ & total length of sinusoid (m) \\
\hline$\alpha$ & thermal diffusivity of fluid $\left(\mathrm{m}^{2} \cdot \mathrm{s}^{-1}\right)$ \\
\hline$\beta_{T}$ & thermal expansion coefficient of fluid $\left(\mathrm{K}^{-1}\right)$ \\
\hline$\lambda$ & thermal conductivity $\left(\mathrm{w} \cdot \mathrm{m}^{-1} \cdot \mathrm{s}^{-1}\right)$ \\
\hline$\mu$ & dynamic viscosity $\left(\mathrm{kg} \cdot \mathrm{m}^{-1} \cdot \mathrm{s}^{-1}\right)$ \\
\hline$v$ & kinematic viscosity $\left(\mathrm{m}^{2} . \mathrm{s}^{-1}\right)$ \\
\hline$\theta$ & $\begin{array}{l}\text { adimensional temperature difference of the } \\
\text { tunnel }\end{array}$ \\
\hline$q$ & $\begin{array}{l}\text { heat flux density exchanged at the tunnel } \\
\text { walls }\end{array}$ \\
\hline$T$ & dimensional temperature of the tunnel $(\mathrm{K})$ \\
\hline$T_{a}$ & dimensional ambient temperature $(\mathrm{K})$ \\
\hline$T_{g}$ & dimensional temperature of the ceiling $(\mathrm{K})$ \\
\hline$T_{f}$ & dimensional temperature of the floor $(\mathrm{K})$ \\
\hline$t$ & dimensional time (s) \\
\hline$u$ & dimensional speed of the fluid \\
\hline$X^{*}=x / L$ & $\begin{array}{l}\text { the ratio of the position } \mathrm{x} \text { over the total length } \\
\text { of the tunnel }\end{array}$ \\
\hline$Y^{*}=y / h_{e}$ & $\begin{array}{l}\text { the ratio of position y over the entrance height } \\
h_{e} \text { of the tunnel }\end{array}$ \\
\hline$U^{*}=U / U_{e}$ & $\begin{array}{l}\text { the ratio dimensional velocity } u \text { over } \\
\text { dimensional inlet velocity } u_{e}\end{array}$ \\
\hline$x, y$ & dimensional Cartesian coordinates (m) \\
\hline \multicolumn{2}{|c|}{ Dimensional numbers } \\
\hline$G_{r}$ & Grashof number; $G=\frac{\beta_{T} g_{p}\left(T_{p}-T_{r}\right) D_{h}^{3}}{v^{2}}$ \\
\hline
\end{tabular}

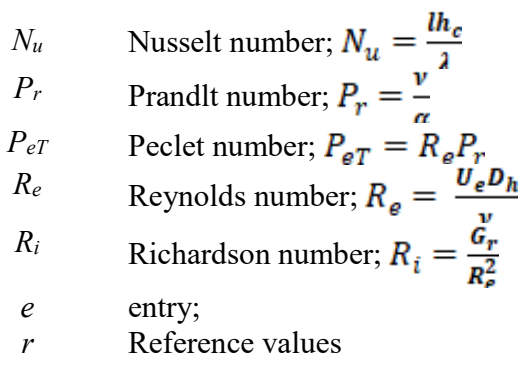

\section{Introduction}

Since the creation of the first tunnels the aim was to improve the transport network and to contribute to the conservation of the environment, thus, taking into account the particular context of the tunnel as a confined environment, whose aeraulic behavior is subject to many factors (traffic, atmospheric conditions, slope ...), many works were conducted to make these buildings more practical and accessible. In order to protect and maintain the tunnels and to protect people inside, investigations like the fire simulation and the ventilation of tunnels were undertaken [14-16]. To make these tunnels safer for the users it is necessary to control the movement of the air and the temperature in order to prevent fires.

In short, the preventive study as the ventilation of the tunnels with the flow of the air in the tunnels has been the center of numerous researches with experimental, theoretical or numerical vocation [1]. We proposed to study the air flow in a tunnel whose floor is sinusoidal with an opening on the horizontal roof.

To carry out this work, the problem has been modeled such that from a time $t_{0}$ the horizontal ceiling and the sinusoidal tread floor of the tunnel are

\footnotetext{
* Corresponding author: intedrame@gmail.com
} 
respectively brought to temperatures $T_{g}$ and $T_{f}$ (with $T_{f}>T_{g}$ ) and the fluid is forced at the inlet with a velocity $\left(\overrightarrow{U_{\rho}}\right)$. The difference of temperature between the floor and the ceiling of the tunnel generates a natural convection that will couple with forced convection giving rise to the mixed convection that we propose to study.

\section{Material and method}

\subsection{Geometry}

In this paper, we propose to model natural convection coupled with forced convection in a tunnel whose characteristics are listed in the Table 1 . To better adapt the problem, we have taken as a model the Soumbédjioune tunnel (Dakar / Senegal) (see Figure 1).

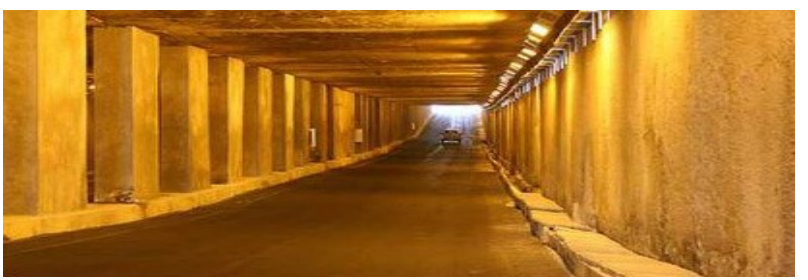

Fig. 1. Dakar / Senegal Soumbédjioune tunnel.

Table 1. Dimensions of the tunnel.

\begin{tabular}{|l|l|}
\hline Total length of the tunnel, $\mathrm{L}$ & $300 \mathrm{~m}$ \\
\hline Length of the sinusoidal, 1 & $200 \mathrm{~m}$ \\
\hline Entrance height, he & $5 \mathrm{~m}$ \\
\hline Width of tunnel & $10 \mathrm{~m}$ \\
\hline Height of the sinusoid, 2a & $2 \mathrm{~m}$ \\
\hline Size of the roof-opening & $2 \times 10 \mathrm{~m}^{2}$ \\
\hline
\end{tabular}

To implement these dimensions, we have drawn the geometry in 3D with Ansys Fluent's geometry modeler, which we presented in Figure 2.

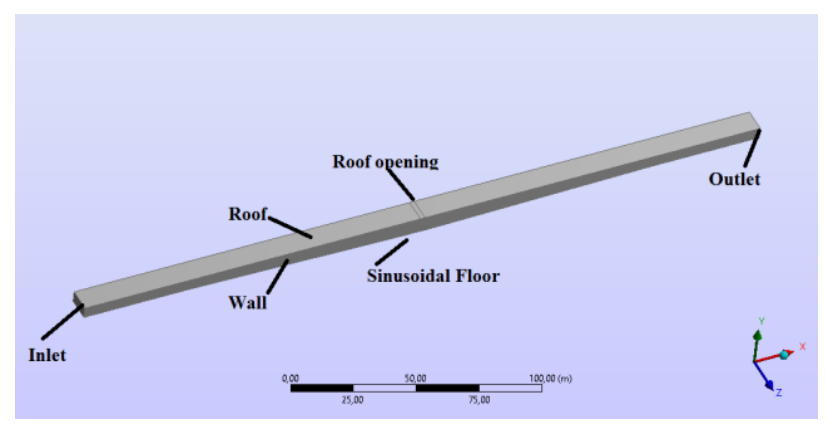

Fig. 2. Tunnel geometry.

\subsection{Mesh}

The grid generation of this geometry was carried out in Ansys Workbench. A hybrid tetrahedral mesh was generated. We made a grid dependence test on several meshes and the one that does not affect the results is composed of 486087 of elements Figure 3.

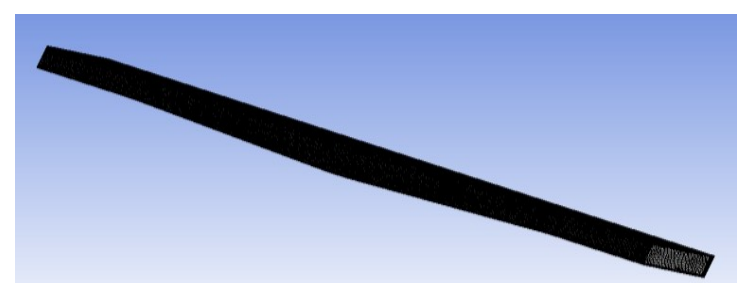

a)

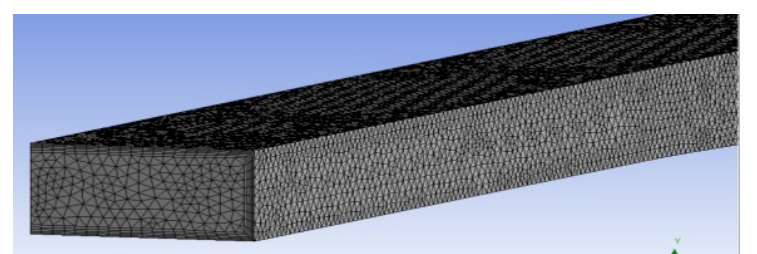

b)

Fig. 3. Tetrahedral mesh used for numerical simulation (different closeups).

\subsection{Boundary conditions and setups}

To model the natural convection, we imposed a floor temperature equal to $35^{\circ} \mathrm{C}$ and the ceiling was maintained to ambient temperature at $25^{\circ} \mathrm{C}$, creating a rise from the floor area to the ceiling.

And as we don't have details of the flow velocity and pressure in the outlet end roof opening, outflow boundary conditions are used to model flow exits in this area. For the rest we gave different values to the velocity at the entrance thus making it possible to study the problem on the three types of convection with different Richardson numbers (Natural, Mixed and forced) (see Table 2).

Table 2. Flow characteristics for different types of convection.

\begin{tabular}{|c|c|c|c|}
\hline Velocity & $\begin{array}{c}\text { Natural } \\
\text { convection }\end{array}$ & $\begin{array}{c}\text { Mixed } \\
\text { convection }\end{array}$ & $\begin{array}{c}\text { Forced } \\
\text { convection }\end{array}$ \\
\hline $\mathrm{U}(\mathrm{m} / \mathrm{s})$ & 0,$01 ; 0,1$ & 1,473 & $20 ; 40$ \\
\hline $\mathrm{R}_{\mathrm{i}}$ & $21700 ; 217$ & 1 & $\begin{array}{c}0,00543 ; \\
0,00136\end{array}$ \\
\hline
\end{tabular}

\section{Validation}

The numerical method $\mathrm{k}-\varepsilon$ realizable used in this work is validated by many studies [3, 4] of turbulent flows with the presence of sinusoid at the level of the floor $[1,2,6$, 8]. Many variations of this method are used to achieve works with a similitude of geometry to our problem. The numerical simulation was carried out in Fluent software 19.0 [7]. The coupled algorithm was used for the pressure-velocity coupling. Also, a second order upwind scheme was considered for the calculation of the 
convective terms. The turbulent model used was $\mathrm{k}-\varepsilon$ Realizable with Standard Wall Functions, a model which respect a physical constraint (complex geometry) and offers the same benefits as the RNG k- $\varepsilon$ viscous model.

After validation of the method, a dynamic validation of the results was carried out for a speed: $U=1.473 \mathrm{~m} / \mathrm{s}$ corresponding to a mixed convection (see Figure 4.a). In order to comply with the previous studies and to obtain a reasonable validation, we took into account the opening on the roof and compared the vertical tunnel velocity profiles before and after opening with the results obtained by K.A. Hafez [3]. (Figure 4.b) and the velocity profile is shown away from the aperture i.e: at position $X^{*}=0.304$ and $X^{*}=0.992$

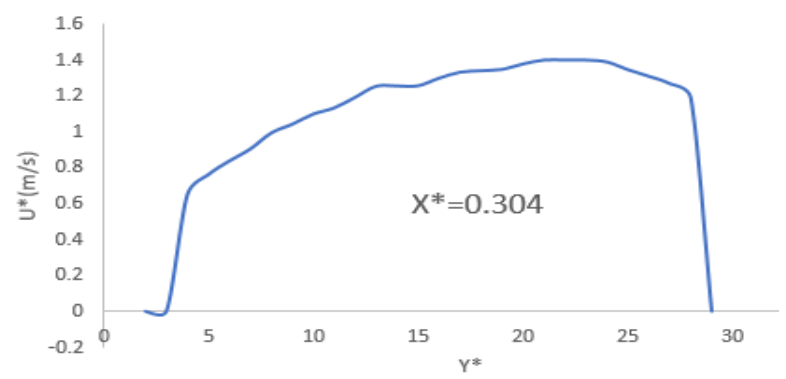

a)

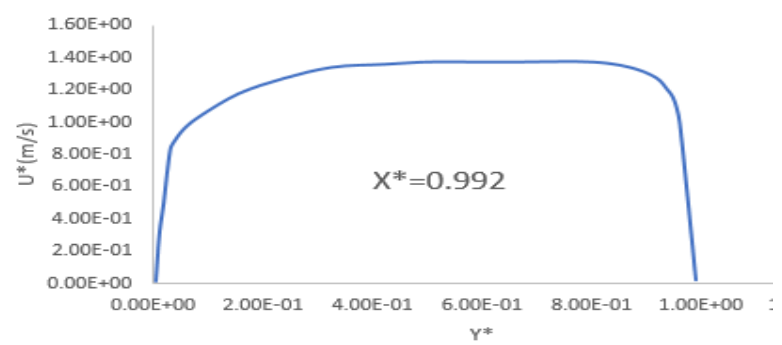

d)

Fig. 4.a. Velocity profile for $X *=0.304$ a) and $X *=0.992$ and c) depending on $\mathrm{Y}^{*}$ current work.

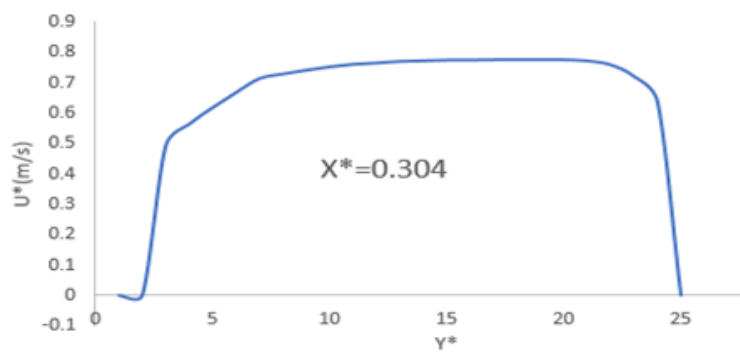

b)

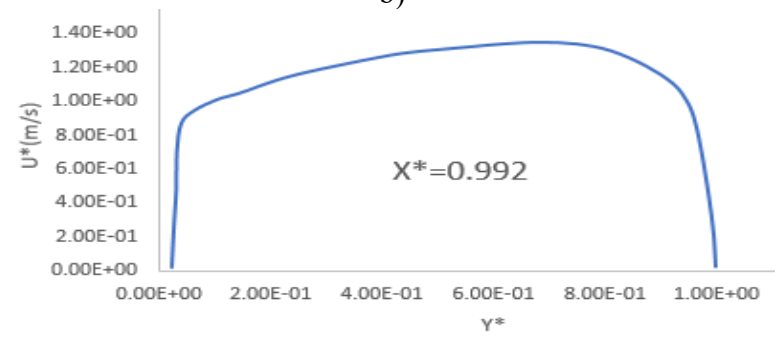

d)

Fig. 4.b. Velocity profile for $X *=0.304$ b) $X *=0.992 d$ ) depending on $\mathrm{Y}^{*}$ work of K.A. Hafez.

\section{Results and discussions}

\subsection{Effect of Richardson's number on velocity and temperature profiles}

The study was done for different mean velocity values, thus giving corresponding Reynolds and Richardson numbers.

The choice of these velocities allowed us to establish three areas of study as listed in Table 3 . This range of $R_{i}$ was selected based on preliminary calculations covering natural-convection, mixed-convection, and forcedconvection dominating regimes. The results are displayed in the following figures by, temperature contours and velocity contours Figure 6, and a centred magnification of the streamlines Figure 5 is then given for different values of the number of Richards. For all the values of Richardson's number taken in our work; we find that the convective heat exchange between the floor and the roof is more important in the second half of the tunnel. For the first two values of the Richardson number $\mathrm{R}_{\mathrm{i}}(\mathrm{a}, \mathrm{b})$ that correspond to the natural convection, we note a favourable rise of warm air from floor to ceiling Figure $5(\mathrm{a}), \mathrm{b})$ ) and that can be explained by the fact of the low values of the velocity $(0.01 \mathrm{~m} / \mathrm{s}, 0.1 \mathrm{~m} / \mathrm{s})$, which a large amount of air mass is evolved on roof opening thus promoting a considerable rise of the hot air to the roof on the second half of the tunnel and this amplitude decreases with increasing velocity. This phenomenon can be explained by the fact that for the smaller values of Richardson, it appears a first recirculation zone on the upper part of the second half of the tunnel Figure 5 (a), b)) which develops with the growth of the velocity. this recirculation zone thus prevents the rise of hot air by natural convection causing the decrease in the amplitude of the hot air mass which is more concentrated towards the floor. For the Richardson number $\mathrm{R}_{\mathrm{i}}=1$ corresponding to the mixed convection Figure $6 \mathrm{c}$ ), there is a sharp decrease in the density of air coming out of the roof opening. This reduction of the velocity at the roof opening promotes an evacuation of the air mass at the exit and at the same time encourages the growth of the primary recirculation zone which has appeared since the first value of the velocity. In addition to the growth of the primary recirculation zone we notice the appearance of a secondary recirculation zone at the lower part of the second half of the tunnel that proves the hypothesis from the beginning. The increase in the amplitude of air mass at the exit is more and more considerable with the reduction of Richardson number $\mathrm{R}_{\mathrm{i}}(\mathrm{d}$, e) which coincides with the forced convection Figure $6(d, e)$. For these two values of the Richardson number, it clearly appears a decrease in temperature on the second half of the tunnel caused by the importance of the air velocity which evacuates heat even reaching the ceiling.

This analysis is validated by Figure 5 (d), e)) which shows that, in addition to the primary recirculation zone, there is a secondary recirculation zone which is pushed towards the tunnel outlet when the velocity increases. 
After validation of the method, a dynamic validation of the results was carried out for a speed: $U=1.473 \mathrm{~m} / \mathrm{s}$ corresponding to a mixed convection (see Figure 4.a).

\subsection{Effect of Richardson's number on local Nusselt number}

To study the influence of the Richardson number on heat transfer, we present in Figure 7 the variation of the number of Nusselt at the level of the floor according to the Richardson number. It can be seen that for all Richardson numbers values there is a large variation in the number of Nusselt at the tunnel entrance. This variation at the entrance of the tunnel can be explained by the fact that it has a significant convective exchange between the cold air $\left(25^{\circ}\right)$ and the hot floor $\left(35^{\circ}\right)$. And as you drive through the tunnel a thermal equilibrium is established between the floor and the air, leading to a considerable reduction in the number of Nusselt. This increase in the number of Nusselt can also be explained by the transition towards the forced convection regime (the relative importance of natural convection becomes negligible for $R_{i}<<1$ ), in this case the heat transfer is ensured mainly by convective fluxes between the air and the floor.

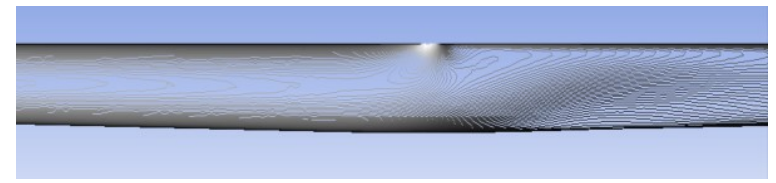

a)

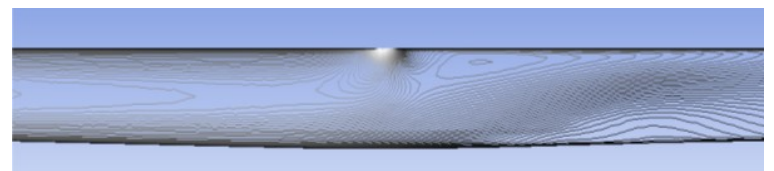

b)

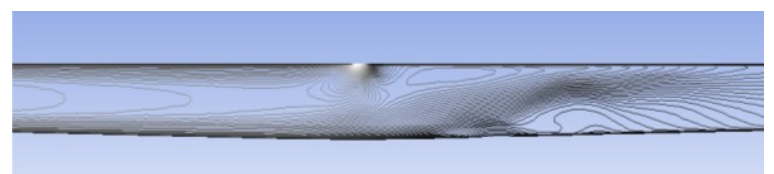

c)

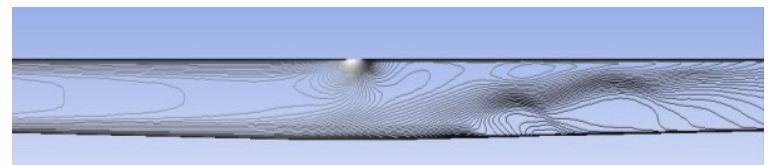

d)

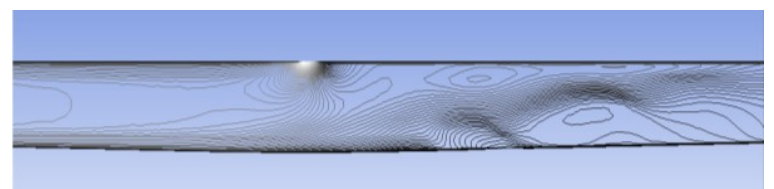

e)

Fig. 5. Velocity profile for $\left.X^{*}=0.304 b\right) X^{*}=0.992 d$ ) depending on $\mathrm{Y}^{*}$ work of K.A. Hafez..

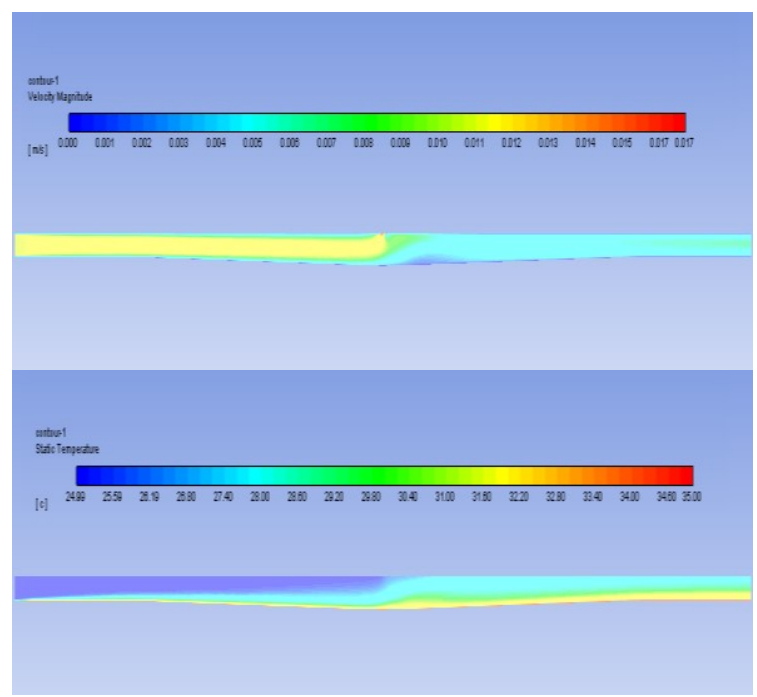

a)

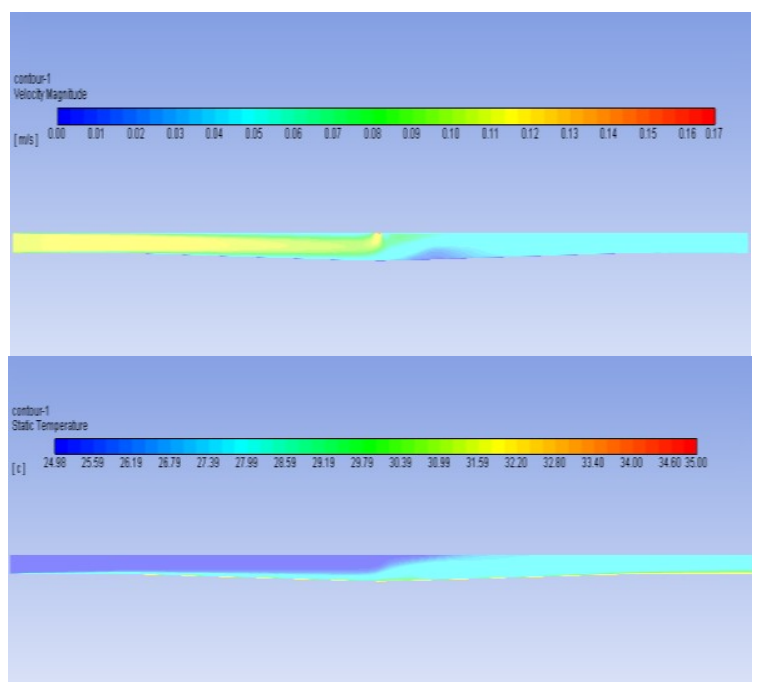

b)

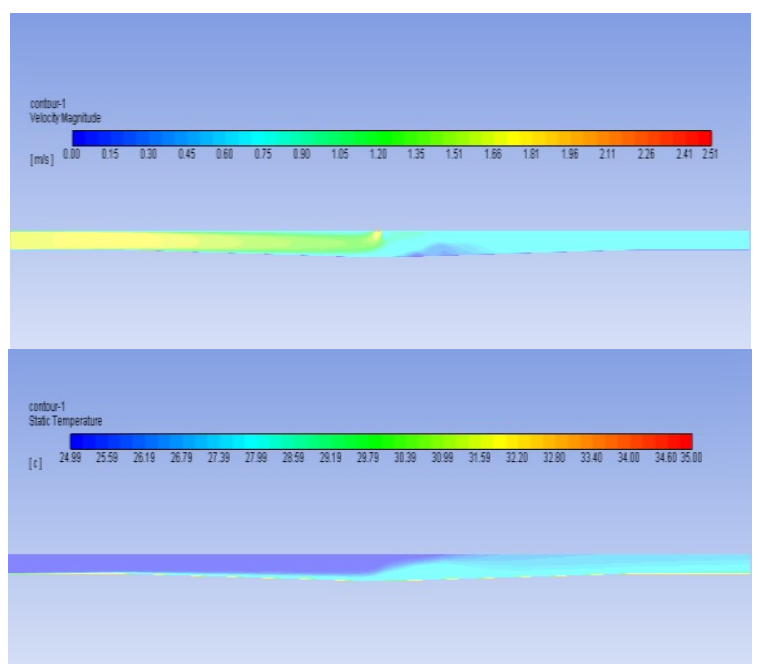

c) 


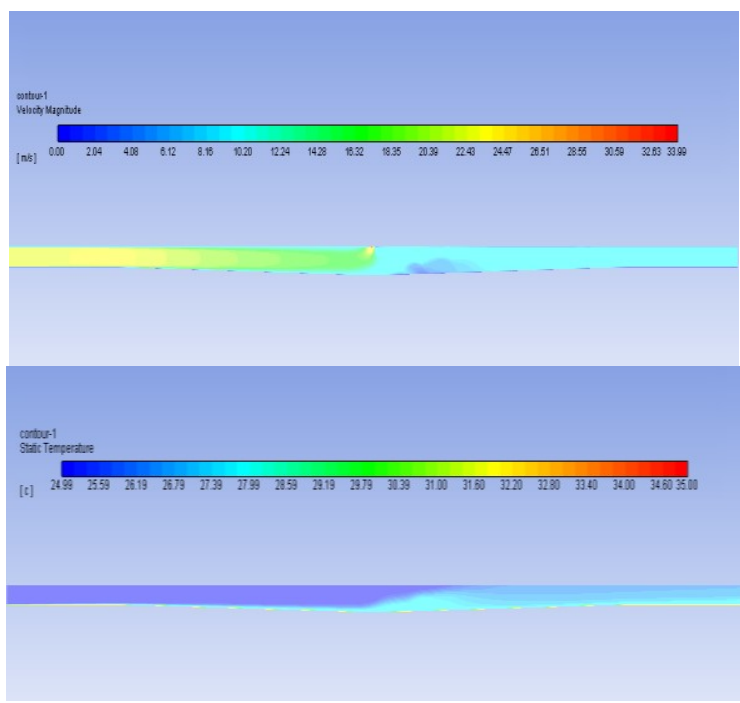

d)

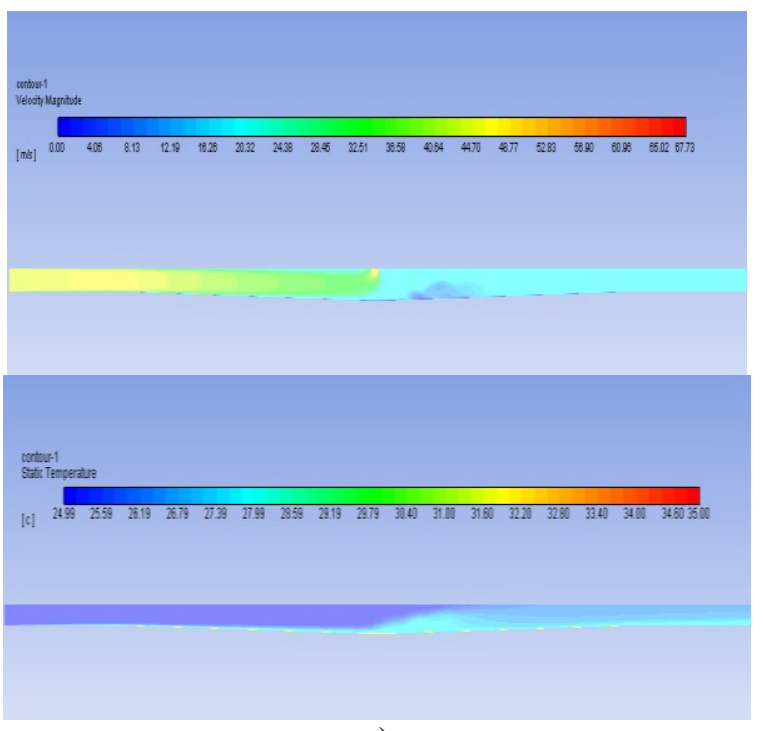

e)

Fig. 6. Velocity and temperature contours obtained for different values of $\operatorname{Ri}: \operatorname{Ri}(a)=21700 ; \operatorname{Ri}(b)=217 ; \operatorname{Ri}(c)=1$; $\operatorname{Ri}(d)=0.00543 ; \operatorname{Ri}(e)=0.00136$.

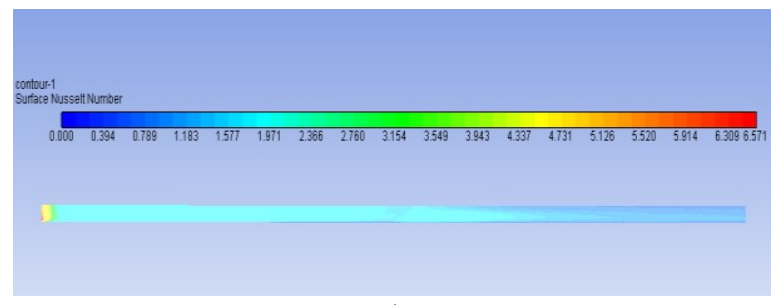

a)

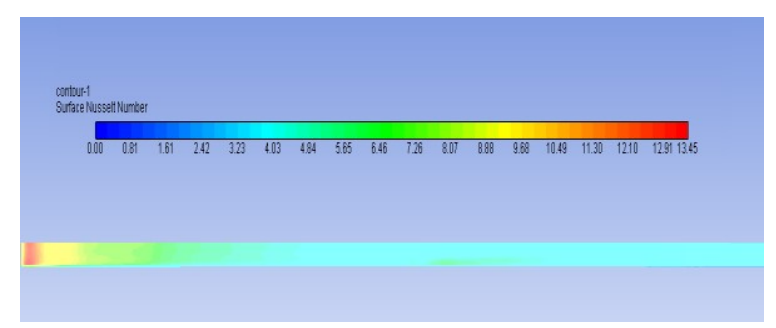

b)

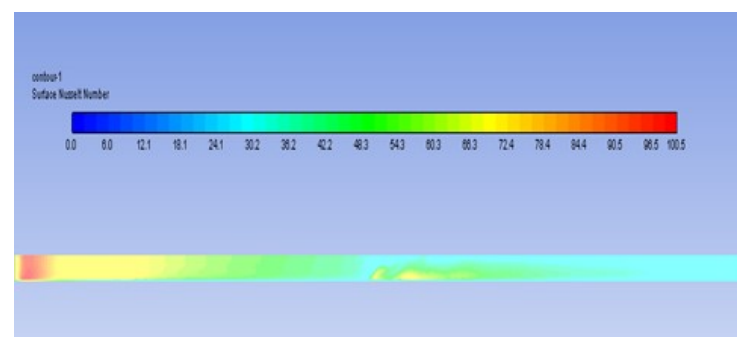

c)

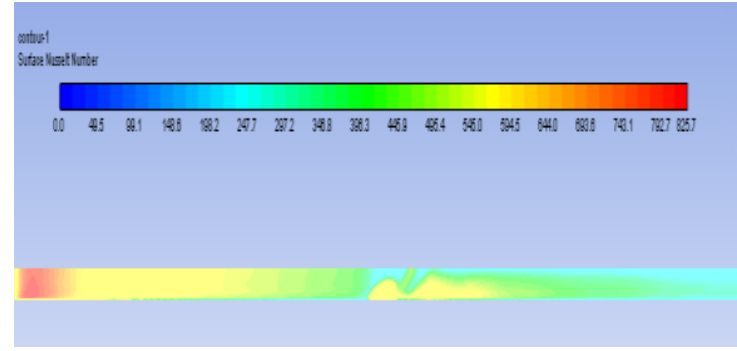

d)

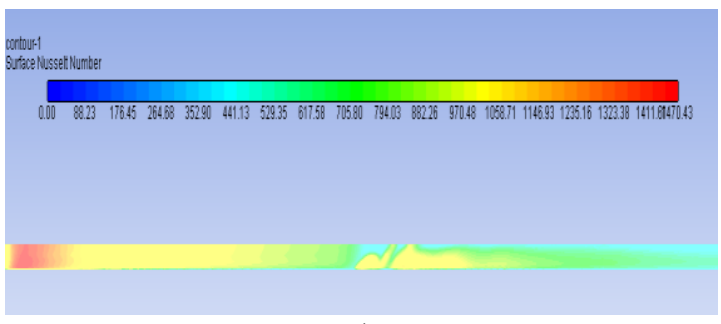

e)

Fig. 7. Local Nusselt number of floor obtained for different values of $R_{i}: R_{i}(a)=21700 ; R_{i}(b)=217 ; R_{i}(c)=1$; $\mathrm{R}_{\mathrm{i}}(\mathrm{d})=0.00543 ; \mathrm{R}_{\mathrm{i}}(\mathrm{e})=0.0013$.

\section{Conclusion}

In the present work, we have carried out the numerical study of the mixed convection of turbulent flow of air in a tunnel whose floor is sinusoidal with an opening in the middle of the horizontal ceiling. Numerical simulation had been carried out in Ansys Fluent 19.0 solver. There results showed that the spatial development of thermoconvective instabilities is greater in the second half of the tunnel regardless of the Richardson number. Thus, it is noticed that as the number of Richardson decreases (tends towards forced convection), a secondary recirculation zone appears on the lower part of the second half of the tunnel. Moreover, the decrease in the amplitude of the convective cells when the Richardson number is increased is supported by the fact that the heat is evacuated more rapidly with the increase of the velocity. In addition, we have also found that the heat exchange is rather assured by convection between the air and the floor when the number of Richardson varies thus leading to an increase in the number of Nusselt on the floor. This work is continuation of a study that takes into account the effect of geometry for different values of the ratio $2 \mathrm{a} / \mathrm{h}$ on the evolution of the velocity and the temperature gradient. 
This work was carried out with the support of the AUF doctoral research grant program Eugen Ionescu in collaboration with the Government of Romania.

And this study is carried out at the Technical University of Cluj-Napoca, Dept. of Mechanical Engineering; Cluj-Napoca 28, Street of Memorendumului, 400114, Cluj-Napoca Romania.

The author thanks greatly Dr. Ing. BODE Florin in Department of Mechanical Engineering at the Technical University of ClujNapoca /Romania for his continuous support and for providing the computational facilities of ANSYS FLUENT package to carry out the present simulations.

\section{References}

1. C. D. (Edmund) Ang, G. Rein, J. Peiro, R. Harrison: Simulating longitudinal ventilation flows in long tunnels: Comparison of full CFD and multi-scale modelling approaches in FDS6 201

2. S.V. PATANKAR: Numerical heat transfer and fluid flow. Taylor \& Francis, (1980)

3. K.A. Hafez, O.A. Elsamni, K.Y. Zakaria: Numerical investigation of the fully developed turbulent flow over a moving wavy wall using $\mathrm{k}-\varepsilon$ turbulence model (2011) 50, 145-162

4. G. K. Ntinas, X. Shen, Y. Wang, G. Zhang: Evaluation of CFD turbulence models for simulating external airflow around varied building roof with wind tunnel experiment BUILD SIMUL (2018) 11: 115-123

5. H. Z. Han, B. X. Li, B. Y. Yu, Y. R. He, F. C. Li: Numerical study of flow and heat transfer characteristics in outward convex corrugated tubes 55 (2012) 77827802

6. P. Cherukat, Y. Na, and T.J. Hanratty: Direct Numerical Simulation of a Fully, (1998) 11: 109-134

7. Fluent, Fluent 19.0 Help

8. K. CHAIB: CFD simulation of turbulent flow and heat transfert over rough surface; Energy Procedia 74 (2015) 909-918

9. O. Elsamni; K. Hafez; K. Abdel-Rahman: Better Predictions of Fully Developed Flow Over Wavy Wall Using Classical K- $\varepsilon$ Model

10. R. J. Calhoun and Robert L. Street: Turbulent flow over a wavy surface; Neutral case journal of geophysical research, vol. 106, no. c5, pages 9277-9293, May 15, (2001)

11. Y. S. Chang and A. Scotti: Turbulent convection of suspended sediments due to flow reversal; journal of geophysical research, vol. 111, (2006)

12. Y. S. Chen: Computation of turbulent flow using an extended turbulence closure model (13 August 2014)

13. Y. S. Chang and A. Scotti: Entrainment and suspension of sediments into a turbulent flow over ripples Journal of Turbulence (May 2003)

14. M. Mann, C. Segalla: cfd-simulation of smoke propagation and ventilation efficiency of tunnel fire incidents; arsenal research, International Conference 'Tunnel Safety and Ventilation, (2002)
15. F. Herrera, L. A.; S. Pineda, J. M.; S. Rivera, U. S.; T. Meza, P. A. \& R. Blas: cfd simulation of obstructed ventilation ports in a subway

tunnel section; international journal of simulation modelling quarterly issn: 17264529

16. P. Lin, Y Zhang, T. Li, Y. L. Si: A Numerical Study on the Impact of Vehicles' Blockage on the Performance of Semi-transversal Smoke Control System in Tunnel Fire; Procedia Engineering 135 (2016) 248 